\title{
POSSÍVEIS CAUSAS PARA OS ERROS DAS ESTIMATIVAS DO SATÉLITE TRMM - ESTUDO DE CASO NA MICRORREGIÃO DE ITAPARICA-PE
}

\author{
ANJOS, Rafael Silva dos - anjos.rsa@gmail.com \\ Universidade Federal do Pernambuco/UFPE
}

\author{
NÓBREGA, Ranyere Silva - ranyere.nobrega.yahoo.com.br \\ Universidade Federal do Pernambuco/UFPE
}

\author{
CANDEIAS, Ana Lúcia Bezerra - analucia@ufpe.br \\ Universidade Federal do Pernambuco/UFPE
}

\begin{abstract}
RESUMO: O satélite Tropical Rainfall Measuring Mission (TRMM) vem sendo utilizado para mensurar a precipitação na região dos trópicos, além de estudar o seu comportamento ao longo do globo. No entanto, existem diferenças entre os dados de postos pluviométricos e essas estimativas, apresentando variações espaçotemporalmente. Diante da afirmativa, o objetivo desse estudo foi analisar as variações espaço-temporais das diferenças entre as estimativas do satélite TRMM com dados de postos pluviométricos na Microrregião de Itaparica-PE, e sua relação com alguns fatores. Para isso, foi necessária a utilização de dados das estações pluviométricas disponibilizadas pela Agência Nacional das Águas para serem comparados com as estimativas do TRMM. Para essa região, foi identificado que em períodos com maiores proporções de chuvas estratiformes, as diferenças apresentam menores valores. Além disso, não houve variações de acordo com o método de coleta dos dados das estações pluviométricas, quantidade precipitada, série histórica, assim como a variação espacial das diferenças não apresentaram um padrão significativo
\end{abstract}

Palavras- chaves: precipitação, postos pluviométricos, convectiva, estratiforme.

POSSIBLE CAUSES FOR THE ERRORS OF THE SATELLITE ESTIMATES TRMM - CASE STUDY IN THE ITAPARICA-PE MICROREGION

ABSTRACT: The Tropical Rainfall Measuring Mission satellite (TRMM) has been used to measure precipitation in the tropics and to study the variations of rain along the globe. However, there are differences between the data of pluviometric stations and the estimates of satellite, with variations spatio-temporal. Thus, the objective of this study was to analyze the spatio-temporal variations of the differences between the TRMM satellite estimates with data of pluviometric stations in the Microregion of Itaparica-PE, and its relation with some factors. For this, it was necessary to use data from the rainfall stations available by the Agência Nacional das Águas (ANA) to be compared with the TRMM estimates. For this region, it was identified that in periods with greater proportions of stratiform rains, the differences present smaller values. In addition, there were no variations according to the method of collecting rainfall data, precipitation quantity, historical series, as well as the spatial variation of the differences did not present a significant pattern.

Keywords: precipitation, rain gauges, convective, stratiform.

\section{INTRODUÇÃO}

A precipitação é um dos elementos essenciais em estudos climáticos, e também em grande parte de estudos ambientais. A sua importância pode abranger as mais variadas atividades humanas, como Dinku et al. (2007) afirma, ela pode ser um recurso crucial para a agricultura. A sua distribuição sobre a superfície terrestre é muito mais complexa que a insolação ou a 
temperatura do ar. Sendo assim, o padrão de distribuição da precipitação sobre o globo depende de diversos fatores, tais como a topografia, a distância de grandes corpos hídricos, a direção e caráter das massas de ar predominantes, entre outros (AYOADE, 2010).

Os processos formadores da precipitação em grande escala estão ligados ao balanço de radiação e ao ciclo energético da atmosfera ao longo do globo. Partindo desse pressuposto, a validação da precipitação é um dos mais importantes elementos no uso de modelos climáticos. No entanto, existem diversas dificuldades para se conseguir um "valor real" da chuva devido a sua acentuada variabilidade espacial e temporal (PARK et al., 2007).

Um dos métodos de medição da precipitação é por meio de pluviômetros, dentre os quais podem ser diferenciados de acordo com a tecnologia integrada ao equipamento. Para Ayoade (2010) o volume de chuva captado por um pluviômetro em determinado local depende de numerosos fatores, tais como a sua altura em relação ao solo, a velocidade do vento e a taxa de evaporação. Segundo o autor, alguns estudos mostram que quanto maior a altura do pluviômetro, menor é o volume de chuva captado (AYOADE, 2010). Segundo o Centro Nacional de Monitoramento e Alertas de Desastres Naturais (CEMADEN, 2016), são três categorias de pluviômetros:

1- Convencionais: elas armazenam a quantidade de chuva, sendo necessária a medição registrada manualmente.

2- Semiautomáticos: mede e armazena a informação sobre a quantidade das chuvas e a leitura é feita a partir de um painel digital.

3- Automáticos: mede, armazena e transmite automaticamente a informação sobre a quantidade precipitada. Em alguns casos, esses tipos de pluviômetros estão integrados a outros instrumentos de medição de elementos climáticos, como no caso das Plataformas de Coletas de Dados (PCD's).

Diante de tecnologias diferenciadas, é válido considerar que as qualidades dos dados podem ser variadas de acordo com o equipamento utilizado. Em termos de disponibilidade de dados observados, alguns órgãos públicos destacam-se nessa tarefa, como o Instituto Nacional de Meteorologia (INMET), a Agência Nacional das Águas (ANA) e a nível estadual, a Agência Pernambucana de Águas e Climas (APAC), sendo esta responsável pelo fornecimento de dados de precipitação de postos pluviométricos ao longo de todo o estado de Pernambuco.

É válido destacar que os dados para essa produção cartográfica na maioria das vezes são oriundos de postos pluviométricos. No entanto, esses dados estão sujeitos a erros humanos, além disso, a representação cartográfica pode ser comprometida devido à má distribuição dos postos pluviométricos por motivos econômicos e de difícil acesso (ANJOS et al., 2016).

Partindo desse princípio, o uso do sensoriamento remoto torna-se uma técnica que contribui para facilitar o planejamento no âmbito de gestão hídrica incluindo prevenção e mitigação dos eventos extremos - além de solucionar os problemas referentes a má densidade dos postos e de possíveis erros nos dados de precipitação.

O satélite Tropical Rainfall Measuring Mission (TRMM) atualmente vem sendo bastante usado para monitorar as chuvas dos trópicos. Sua missão 
consiste por avaliar as estimativas das chuvas convectivas e estratiformes com o intuito identificar a dinâmica da chuva numa resolução que permite avaliar o espaço sem descontinuidades e ausência de dados a cada 3 horas. Seus dados interpolados podem gerar mapas de estimativas de chuva que auxiliam na interpretação e na análise dos sistemas que originaram determinados eventos (NASA, 2015).

Apesar da contribuição do TRMM para levantamento de dados pluviométricos, alguns trabalhos mostram que as acurácias desses dados tendem a variar de acordo com a localização geográfica e sazonalidade da precipitação. (ANJOS et al., 2013; SOARES et al., 2016; PEREIRA et al., 2013). Algumas hipóteses para a variação espaço-temporal dos erros das estimativas do satélite TRMM são levantadas por esses autores, podendo elas serem oriundas de falhas humanas e/ou dos sensores a bordo do satélite. Avaliando a consideração desses autores, pode-se destacar como possíveis causas desses erros: falhas humanas, quantidade da precipitação, sazonalidade das chuvas, tipos de chuvas, qualidade dos pluviômetros.

A microrregião de Itaparica, localizada na mesorregião pernambucana do Sertão do São Francisco, é uma das regiões mais secas do estado. Embora tenha disponibilidade de água oriunda do Rio São Francisco, a poucos quilômetros de distância do seu curso é perceptível como a baixa e concentrada precipitação afeta a população residente nos municípios que a compõe, comprometendo a agricultura, pecuária e o consumo humano de água. É válido ressaltar que uma maior disponibilidade de dados climáticos representados cartograficamente possibilita que estratégias sejam tomadas para mitigar os efeitos da escassez de água de maneira mais efetiva, pois identificaria as áreas que demandariam de uma política pública mais direcionada (ANJOS, 2017).

Por isso, torna-se necessária uma maior disponibilidade de dados pluviométricos, sendo estimados ou observados para auxiliar em medidas mitigadoras de eventos extremos. No caso das estimativas, é relevante a compreensão das variações espaço-temporais dos erros inerentes ao levantamento das chuvas. Assim, entender as possíveis causas da origem desses erros, auxiliam na correção e validação desses dados.

Portanto, o objetivo desse artigo foi identificar as variações espaçotemporais das diferenças entre as estimativas do satélite TRMM com os postos pluviométricos e sua a relação com os métodos de coleta de dados de precipitação, tipos de chuvas (convectiva e estratiforme), quantidade precipitada, e o intervalo da série histórica de dados.

\section{REFERENCIAL TEÓRICO}

\subsection{BREVE HISTÓRICO DO SATÉLITE TRMM}

O satélite Tropical Rainfall Measuring Mission (TRMM) foi desenvolvido através de uma parceria entre a NASA e a Agência Japonesa de Exploração Aeroespacial (JAXA), sendo lançado em 27 de novembro de 1997 com o objetivo específico de monitorar e estudar a precipitação nos trópicos, além de verificar como a mesma se comporta no clima no clima global. A órbita polar baixa do satélite (inicialmente $350 \mathrm{~km}$ e desde 2001, $403 \mathrm{~km}$ ), juntamente com o período 
curto de translação (91 minutos) permite uma alta resolução temporal e espacial do imageamento (NASA, 2015).

Os dados de satélites compreendem um núcleo de informações que permite estimar a precipitação em escala global, sendo possível criar estimativas a partir de apenas um sensor, ainda que a utilização de mais sensores possa aumentar a acurácia cobertura e resolução dos dados.

Ao todo são cinco sensores a bordo do satélite: o Visible Infrared Radiometer (VIRS), TRMM Microwave Imager (TMI), Precipitation Radar (PR), Lightning Imaging Sensor (LIS) e o Clouds and the Earth's Radiant Energy System (CERES) (Figura 1).

O VIRS é um radiômetro de varredura de faixa transversal passivo, com cinco canais centrados nos comprimentos de ondas $(0,63),(1,6),(3,75),(10,8)$ e $12 \mu \mathrm{m}$, fornecendo observações de alta resolução espacial da cobertura das nuvens, a temperatura do topo da nuvem e o seu tipo (MORALES e ALBRECHT, 2014).

O TMI é um radiômetro de micro-ondas passivo que fornece informações sobre o conteúdo integrado da coluna de precipitação, água líquida da nuvem, intensidade da chuva e os tipos de precipitação (convectiva e estratiforme).

O PR foi o primeiro radar projetado especificamente para monitoramento de chuvas para operar a partir do espaço. Apesar do pequeno histórico de dados e sofrer das mesmas incertezas acerca da acurácia das estimativas de chuva como fazem radares baseados em terra, o sensor emitiu informações do tamanho das gotículas nas nuvens, oferecendo informações da estrutura vertical da precipitação (KUMMEROW, 2000).

O LIS é um sensor óptico passivo que detecta e localiza eventos de raios na faixa do oxigênio $(0,777) \mu \mathrm{m}$.

Os dados do instrumento CERES podem ser usados para estudar a energia trocada entre o Sol, a atmosfera e a superfície terrestre. No entanto, o sensor só funcionou de janeiro de 1998 à março de 2000, portanto, o registro de dados disponíveis é bastante curto (NASA, 2015).

\subsection{ALGORITMO 3B43}

Os instrumentos de medição de chuva sobre 0 satélite incluem 0 Precipitation Radar (PR), um radar de varredura eletrônica operando a 13,8 $\mathrm{GHz}$; TRMM Microwave Image (TMI), um radiômetro de micro-ondas no canal nove; e o Visible and Infrared Scanner (VIRS), um radiômetro no canal cinco do visível/infravermelho.

A proposta do algoritmo é produzir taxas de precipitação, erro das estimativas do satélite com outras fontes de dados e estimativas mensais de chuva. Para chegar ao resultado, são combinadas estimativas independentes do TMI, do Radiômetro de Escaneamento de Microondas Avançado, Sensor de Imageamento do Microondas, Sonda de Microondas da Umidade, do acumulado mensal de precipitação do Centro de Estações Pluviométricas Global, dentre outros. Todos os dados de entrada do microondas são intercalibrados para o TRMM Combined Instrument (TCI) (Produto para estimativas do 3B31); as estimativas do Infravermelho são computadas tomando por base o histograma 
correspondente a média mensal e então, as faltas de dados de 3 em 3 horas do microondas são complementadas pelas estimativas do infravermelho (NASA, 2015).

Depois do pré-processamento, os dados com resolução temporal de 3 horas são somados para um mês e combinados com dados de estações de maneira que as estimativas fiquem melhores. Os resultados finais do algoritmo 3B43 são estimativas mensais, com resolução espacial de $0,25^{\circ} \times 0,25^{\circ}$, abrangendo até as latitudes $50^{\circ}$ Norte e $50^{\circ}$ Sul (NASA, 2015).

\subsection{ALGORITMO 3A25}

O algoritmo $3 A 25$ é um dos produtos resultante da combinação dos sensores TMI e PR. Ele por sua vez, disponibiliza vários tipos de dados cada qual representado por uma variável. Dentre os principais dados desse algoritmo seria as taxas $(\mathrm{mm} / \mathrm{h})$ dos tipos de chuvas convectivas e estratiformes, além da quantidade total precipitada na superfície $(\mathrm{mm})$.

O PR emite um pulso de energia e ao retornar ela é proporcional ao diâmetro à sexta potência da gota iluminada pelo sensor, sendo este um dos métodos para avaliar o tipo de precipitação; quanto maior refletividade, maior será a gota e mais chance de a mesma ser proveniente de uma nuvem convectiva.

Outro processo de avaliação para detecção das chuvas convectivas e estratiformes é por meio da análise do perfil vertical das nuvens. Em condições de menor desenvolvimento vertical das nuvens, as partículas tendem a ter um movimento mais suave por meio da subsidência, favorecendo a uma certa estabilidade das isotermas. Por isso, quando se tem a presença de uma banda brilhante na atmosfera, as precipitações que são geradas nessa região são consideradas estratiformes (ANJOS, 2017).

Essa banda brilhante é caracterizada por ser uma faixa de alta refletividade devido ao derretimento de gelo agregado. Esse processo é justificado pois acima da isoterma de $0^{\circ} \mathrm{C}$, o gelo cai numa velocidade terminal relativamente mais lenta e logo que o gelo atinge essa isoterma, o mesmo começa a derreter de fora para dentro. Quando ocorre esse processo, a superfície da partícula de gelo fica, momentaneamente, com água em estado líquido enquanto o interior permanece no estado sólido. Quando o radar detecta essa partícula, o identifica como uma grande gota de água, podendo aumentar significativamente a refletividade do radar (OLIVEIRA, 2014).

Com a queda da neve, e consequentemente o seu aumento de velocidade e diminuição do seu tamanho a refletividade do radar começa a diminuir em níveis mais baixos. Ao fim, ao serem analisadas o perfil vertical da refletividade, é observada uma faixa com alta refletividade que pode alterar significativamente o resultado da estimativa de precipitação. Por isso, justificase a utilização de métodos para correção desse possível erro (OLIVEIRA, 2014).

Partindo dos pressupostos acima podemos fazer um pequeno esboço para classificação das chuvas (ARAÚJO, 2015):

I - Quando a Banda brilhante existe, a chuva é considerada estratiforme. 
II - Quando a Banda Brilhante não é detectada, e o valor de refletividade ( $Z$ ) excede $40 \mathrm{dBZ}$ ou o topo da nuvem está a mais de $15 \mathrm{~km}$ é considerada como chuva convectiva.

III - Quando o eco do radar não é forte para ser considerado como convectivo, quando não é detectado Banda Brilhante e quando não existem ruídos, a chuva é classificada como outros.

\subsection{ALGUMAS APLICAÇÕES DO TRMM PARA ESTIMATIVAS DE PRECIPITAÇÃO}

Alguns trabalhos que utilizam dados do TRMM vêm se destacando pela validação dessas estimativas comparando-as com dados observados, além da sua aplicabilidade nas mais variadas atividades humanas, incluindo agricultura e uso e ocupação do solo.

Baseando-se nessas aplicabilidades, Costa e Souza (2012) avaliaram a qualidade das estimativas do TRMM para subsidiar na avaliação da mudança no uso do solo em Ourém, no Pará. A partir da confirmação da boa qualidade estatística das estimativas, os autores conseguiram identificar as variações espaciais no uso do solo, a partir dos dados de precipitação. No que concerne a utilização das estimativas para avaliação agrometeorológica, Fuzzo et al., (2015) avaliaram a qualidade dos dados do satélite e verificaram que a sua qualidade na acurácia e na resolução espacial permitem o seu uso como dados de entrada para modelagem de produtividade de soja no estado de São Paulo.

Anjos e Nóbrega (2013) compararam dados observados no estado de Pernambuco com as estimativas diárias do satélite TRMM entre os anos de 1998 e 2010. As maiores diferenças foram encontradas próximos ao litoral do estado, onde foram subestimadas as estimativas, enquanto nos pontos situados mais ao interior possuíram as melhores estimativas, porém com superestimação.

Com resultados semelhantes, Soares et al. (2016) verificaram que as variações espaciais e sazonais das chuvas estimadas no estado da Paraíba são próximas dos dados observados. É válido acrescentar que os autores encontraram também uma tendência de diminuição dos erros de pontos em regiões litorâneas para os que estão localizados no interior do estado. Além disso, eles concluíram que no período seco na Paraíba, as estimativas tendem a se aproximar dos dados observados.

Abrangendo escalas geográficas maiores, Pereira et al. (2013) identificaram que a variação espacial e sazonal das chuvas deu-se de maneira diferenciada de acordo com as Regiões no Brasil. No Nordeste, os valores das estimativas do satélite TRMM superestimaram os dados observados em aproximadamente $9 \%$. É válido acrescentar que algumas regiões como o Centro-Oeste e o Norte, tiveram correlações estatísticas maiores no período mais seco do ano.

No entanto, Louzada et al. (2015) identificaram que as estimativas na Bacia do Rio Doce, localizada entre os estados de Minas Gerais e Espírito Santo, tendiam a ter menores correlações estatísticas nos períodos secos (Junho, Julho, Agosto). Tais evidências contraditórias acerca do período que o satélite tende a estimar melhor as chuvas, reflete uma complexidade nas possíveis causas que promovam essa variação espacial e sazonal dos erros. 
Com o intuito de verificar quais os tipos de chuvas (estratiformes e convectivas) atuantes no estado de Pernambuco, Anjos et al. (2016) perceberam que as intensidades das chuvas estratiformes diminuem a medida que se distanciam do litoral, o que não acontece com as chuvas convectivas. Tal fato poderia estar relacionado às variações dos erros das estimativas ao longo do estado de Pernambuco como Anjos e Nóbrega (2013) identificaram.

Buscando análises em escalas cartográficas maiores, Anjos et al. (2016), verificaram que em Petrolândia, na microrregião pernambucana de Itaparica, as estimativas tendiam a se distanciar dos dados observados nos meses mais secos (Junho à Agosto), evidenciando semelhanças acerca do período de maiores erros com o trabalho de Louzada et al. (2015). Os autores ainda identificaram que as taxas de intensidade das chuvas convectivas e estratiformes são mais evidentes na estação chuvosa, estando as chuvas formadas por processos de convecção em maiores quantidades. Além disso, foi percebido que apesar de em março a quantidade precipitada de chuvas convectivas tem seu maior pico no ano, as maiores proporções são de chuvas estratiformes.

Javanmard e Jamli (2015) utilizaram as estimativas do TRMM no Irã e verificaram que haviam maiores superestimações durante os meses mais frios. Utilizando comparações de chuvas mensais, os autores identificaram que as contribuições das chuvas convectivas são maiores, em comparação com a estratiforme, no entanto, essas contribuições tende a ser maior durante os meses frios.

Ochoa et al. (2014) utilizaram as estimativas das versões 6 e 7 do algoritmo 3B42 no oeste do Equador e Peru identificaram que a gênese das chuvas e suas variações espaciais iriam contribuir para que a acurácia das estimativas se diferenciassem de acordo com sua localização geográfica.

Indur e Kumar (2014) fizeram análises das frequências do TMI, sensor do satélite TRMM responsável por levantar dados a partir da radiação microondas com 20 combinações de canais, para avaliar a estimativa das chuvas na Índia. Perceberam que as estimativas se aproximam mais dos dados observados em canais de baixas frequências do que os canais com frequência maior que 85 Ghz.

Duan et al. (2015) analisaram os dados de postos pluviométricos localizados nas Montanhas Apalachianas comparando-os com as estimativas de precipitação e os tipos de chuvas estratiformes e convectivas atuantes na região. Houve uma concordância entre os dados, mas essa será determinada pelo regime de chuvas, incluindo as características das chuvas e sua intensidade. Os autores abordaram a importância em considerar as características do terreno para o satélite obter bons resultados nas estimativas.

A análise feita por Collischonn (2006) encontrou erros relativos de $9 \%$ para a precipitação acumulada anual comparada por dados de superfície, sendo esse resultado aproximado com o de Nóbrega et al. (2008) em que comparou os dados do TRMM com os de "Climate Prediction Center" (CPC), assim como os das estações meteorológicas da Sub-Bacia da Amazônia Ocidental. 


\section{MATERIAIS E MÉTODOS}

\subsection{CARACTERIZAÇÃO DA ÁREA DE ESTUDO}

A área de estudo abrange a Microrregião de Itaparica que está inserida no Semiárido Brasileiro e faz parte das microrregiões do estado de Pernambuco (Figura 1). É composta por sete municípios: Itacuruba, Belém de São Francisco, Floresta, Jatobá, Tacaratu, Itacuruba e Carnaubeira da Penha. Sua população ao total é de 134.933 habitantes (IBGE, 2016).
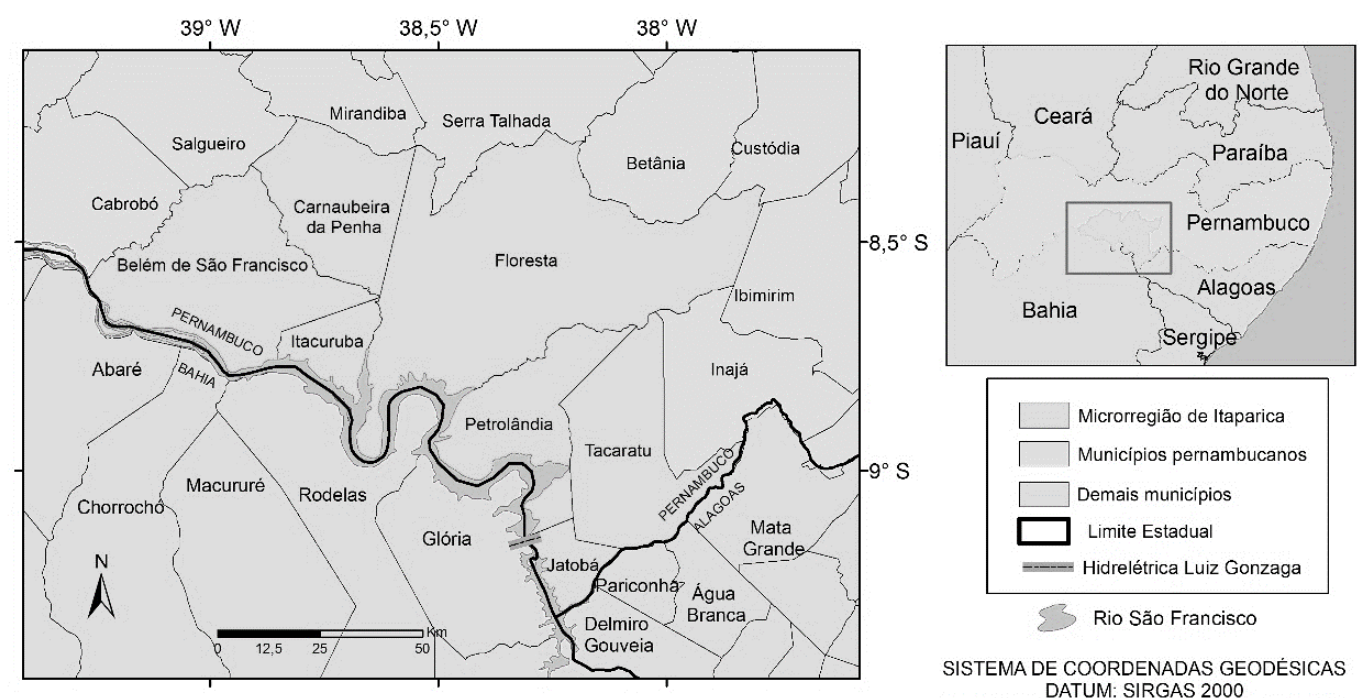

SISTEMA DE COORDENADAS GEODÉSICAS DATUM: SIRGAS 2000 BASE DE DADOS DO INSTITUTO BRASILEIRO DE GEOGRAFIA E ESTATISTICA

Figura 1 - Localização da Microrregião de Itaparica.Elaborado por: Rafael Anjos, 2016.

\subsection{CLIMA}

Considerando todos os municípios da microrregião, a precipitação média anual é de 516,4 mm (UFCG, 2016), sendo extremamente concentradas ao longo do ano. Além da pouca pluviosidade, a média anual da temperatura média do ar de $25,5^{\circ} \mathrm{C}$ (UFCG, 2016), torna a perda de água bastante acentuada através da evapotranspiração.

Baseando-se na classificação climática de Köppen, o tipo climático na região é BShw, caracterizada por ser um clima semiárido, seco e quente com chuvas que abrangem o período de verão e outono (Figura 2). É válido ressaltar que a percepção do povo do semiárido diante das condições climáticas, o fazem designar o verão-chuvoso de "inverno", considerando o "verão" (inverno meteorológico) quando os rios intermitentes não possuem água em seus leitos (AB'SABER, 2003). 


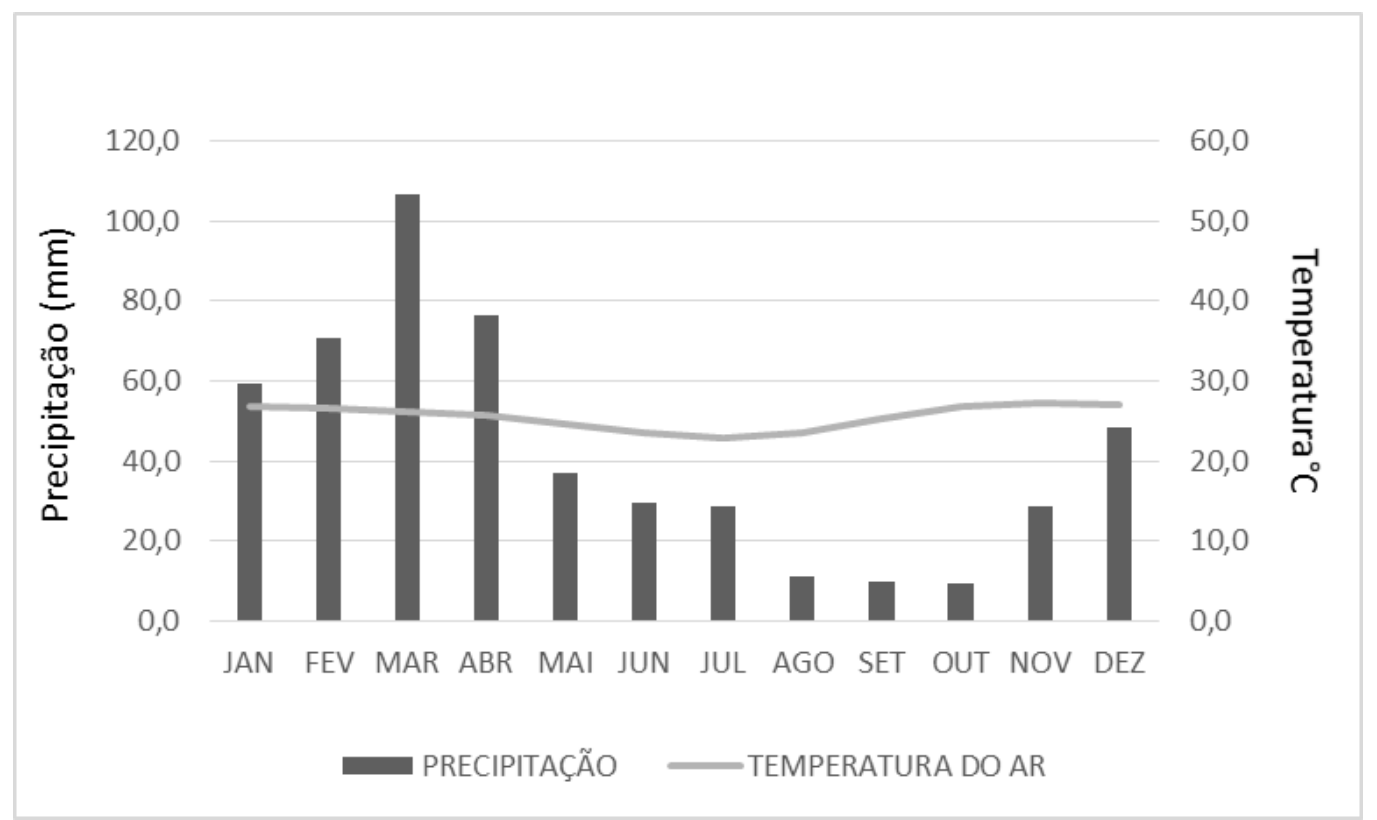

Figura 2 - Climograma da Região de Itaparica baseados nas médias anuais dos municípios. Fonte: UFCG, 2016. Elaborado pelo autor.

\subsection{DADOS DOS POSTOS PLUVIOMÉTRICOS}

Os dados das estações pluviométricas para comparação com as estimativas estão disponibilizados no banco de dados da Agência Nacional de Águas (ANA). Foi preciso fazer uma análise preliminar dos dados visto que eles estavam suscetíveis a descontinuidade na série temporal. Para fazer uma análise mais eficiente (Figura 3), foram incluídos dados de precipitação de municípios que estão no entorno da região. É válido salientar que os dados dos postos pluviométricos possuíam a série histórica completa, sem a necessidade de preenchimento.

\subsection{DADOS DAS ESTIMATIVAS DO SATÉLITE TRMM}

Para comparação com os dados das estações pluviométricas foram utilizadas as estimativas do algoritmo 3B43, responsável pelas estimativas de precipitação mensal.

Com o intuito de analisar a relação das diferenças entre os dados observados e estimados com os tipos de chuvas atuantes, foram utilizadas as estimativas do algoritmo 3A25, que apresenta as taxas mensais de chuvas convectivas e estratiformes.

As estimativas de ambos algoritmos são disponibilizados gratuitamente pela NASA. Foi necessário o uso do software gratuito GraDS, que permite a visualização de dados em formato binário. Para gerar os dados em arquivo ttxt e posteriormente trabalha-los no Excel, foi elaborado um GRADS Script que permite a conversão de arquivo binário para arquivo .txt (NETO e NÓBREGA, 2009). 


\subsection{SÉRIE TEMPORAL A SER ESTUDADA}

Para a pesquisa, foram utilizados os dados de precipitação observada e estimada de 01 de janeiro de 1998 à 31 dezembro de 2014. É válido considerar que, em alguns postos pluviométricos, a série histórica dos dados corresponde a uma parcela dentro do período já mencionado, devido a ausência de dados observados em alguns anos.

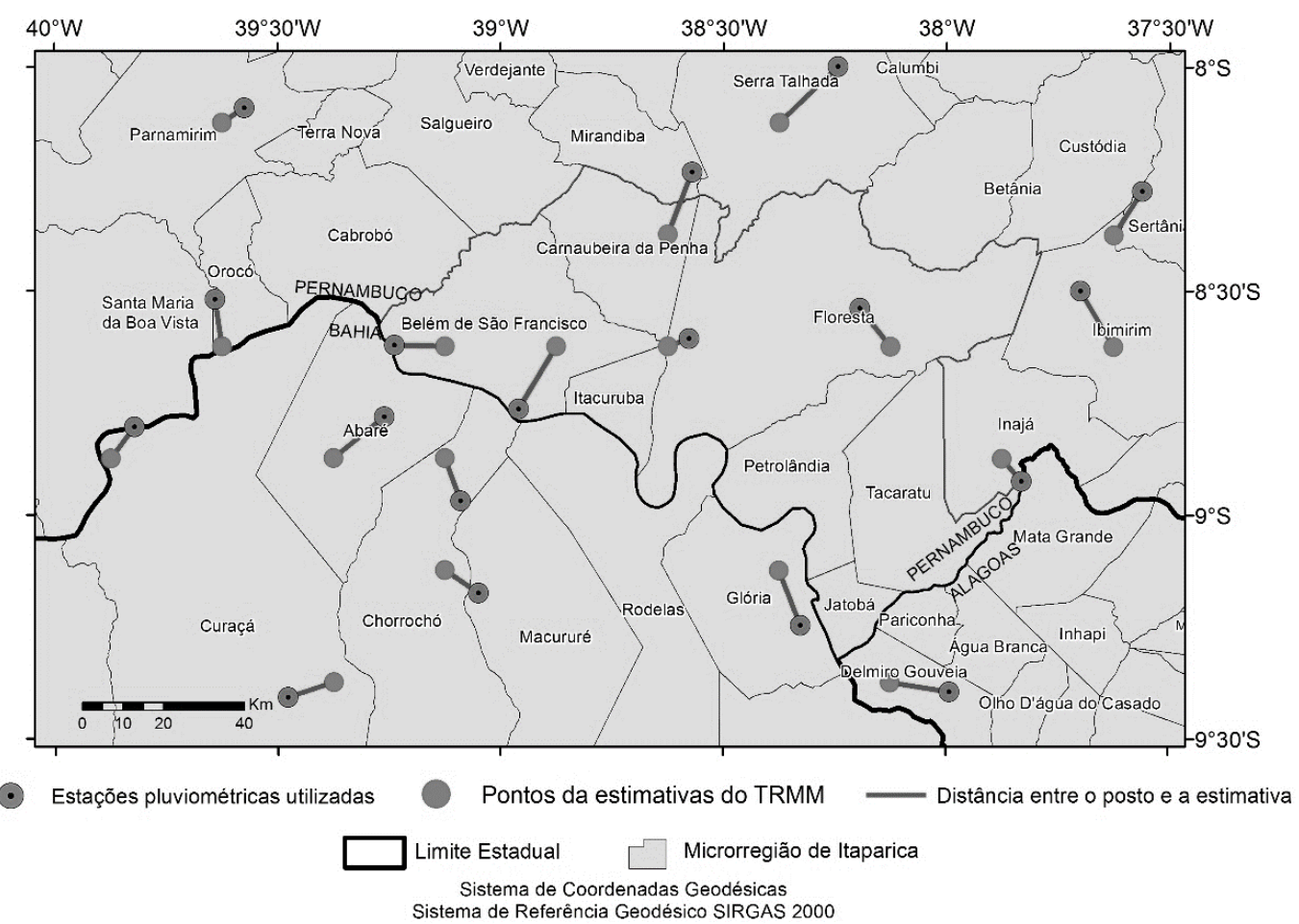

Figura 3 - Postos pluviométricos e pontos das estimativas utilizados. Elaborado por: Rafael Anjos (2016).

\subsection{METODOLOGIA}

A princípio, foi feita a comparação dos acumulados das estimativas do algoritmo 3B43 com os dados dos postos pluviométricos e assim, verificar a acurácia das estimativas em relação a sua variabilidade espaço-temporal. Para análise estatística, foi utilizado o método comparativo baseado no trabalho de DINKU et al. (2007). A seguinte análise estatística baseou-se nas Equações 1, 2 e 3: 


$$
E M=\frac{1}{N} \sum(\text { Pest }- \text { Pobs })
$$

$$
\begin{aligned}
& \text { REQM }=\sqrt{\frac{1}{N} * \sum(\text { Pest }- \text { Pobs })^{2}} \\
& P E=1-\frac{\sum(P e s t-P o b s)^{2}}{\sum(P o b s-\overline{P o b s})^{2}}
\end{aligned}
$$

Em que a (Pest) são as estimativas do TRMM, (Pobs) são os dados observados dos postos pluviométricos, (Pobs) é a média dos dados observados, e (N) o número de meses para o ano. O Erro Médio (1) corresponde a diferença entre a precipitação estimada e observada por mês, em $\mathrm{mm}$. A Raiz do Erro Quadrático Médio (2) corresponde a precisão e a acurácia das estimativas e será representada em $\mathrm{mm} / \mathrm{mês}$, a mesma torna relevante para análise em valores absolutos da diferença, sem a existência de números negativos. A Pontuação de Eficiência (3) pode variar do mínimo infinito até o valor de 1 . Valores negativos mostram que as estimativas tiveram baixo desempenho em quantificar a chuva. Valores próximos de 0 , mostram que tanto as estimativas quanto os dados observados estão próximos do valor real da chuva. Valores próximos de 1 , evidenciam o fato da existência de baixos erros mesmo com uma alta variabilidade da chuva, mostrando a boa habilidade do satélite em quantificar a chuva mesmo em situações que o forçam a ter um erro considerável.

Após essa etapa, foi necessário o acesso aos relatórios das estações pluviométricas da ANA, de modo que fosse possível analisar a qualidade das estimativas com os tipos de coleta de dados e as entidades operadoras e de que maneira essas varáveis estariam correlacionadas entre si.

Para análise da correlação entre os erros das estimativas e os tipos de precipitação, foi necessária uma análise pontual, cujo posto pluviométrico está localizado na sede do município de Belém de São Francisco. Para tal relação, foi considerada a proporção da diferença, entre as estimativas e os dados observados, diante da média mensal da precipitação estimada e observada. Esse método permite uma análise que seja de acordo com a quantidade precipitada em um determinado mês pois, um mesmo erro em um mês seco não pode ter o mesmo peso em um mês chuvoso. O mesmo método de proporção foi utilizado para os tipos de chuvas, de maneira que fosse avaliado a predominância dos tipos de chuvas em cada mês ou ano.

Além disso, foram correlacionados os valores percentuais da diferença anual com a quantidade anual precipitada e as taxas anuais de chuvas convectivas e estratiformes. 


\section{RESULTADOS E DISCUSSÕES}

\subsection{PRECIPITAÇÃO ESTIMADA E OBSERVADA ACUMULADA DE ACORDO COM OS PERÍODOS DISPONÍVEIS}

De modo geral, as estimativas do TRMM superestimaram os dados de todos os postos pluviométricos utilizados. Essa superestimativa de postos pluviométricos que estão localizadas distantes do litoral já tinha sido percebida por SOARES et al., (2016) e ANJOS e NÓBREGA (2013). Tal fato pode estar relacionado com os diferentes tipos de chuvas atuantes entre as regiões litorâneas e as regiões mais distantes do litoral.

Ao analisar o acumulado de precipitação estimada e observada em todos os postos pluviométricos analisados, de acordo com a disponibilidade da série histórica dos dados, foi observado que o menor erro foi no município de Delmiro Gouveia, em Alagoas, com erro médio de 4,69 mm/mês (Tabela 1).

O município de Abaré, localizado na Bahia, foi o que apresentou o maior erro médio por mês, apresentando $22,3 \mathrm{~mm}$. Tal erro torna-se considerável pois a média de precipitação nessa região é bastante limitada $(516,4 \mathrm{~mm})$. Se expandirmos esse erro para um ano, pode-se ter uma diferença entre as estimativas e os dados observados de aproximadamente $268 \mathrm{~mm}$. É válido ressaltar que o período disponível foi de 2003 a 2014, diferenciando-se de Delmiro Gouveia (1998-2014).

Se forem consideradas apenas os postos que estão nos municípios da Microrregião de Itaparica, o que estava localizado no distrito de Ibó - em Belém do São Francisco - foi o que teve o menor erro das estimativas com 7,69 $\mathrm{mm} / \mathrm{mês}$. A maior diferença entre os dados estimados e observados na microrregião foi na sede do mesmo município, com 11,43 mm/mês.

É válido ressaltar que o período dos dados não é um fator determinante para melhores resultados, visto que postos que tiveram dados com maiores períodos (Inajá) tiveram quase os mesmos REQM que os postos com menores períodos (Chorrochó). Isso descarta a possibilidade de um maior período dos dados terem influência no cálculo da acurácia das estimativas.

Tabela 1 - Precipitação acumulada observada e estimada em $(\mathrm{mm})$, diferença $(\mathrm{mm})$, erro médio ( $\mathrm{mm} / \mathrm{mês}$ ), raiz do erro quadrático médio (REQM), pontuação de eficiência (PE) e período dos dados em ordem crescente do erro médio, em destaque os municípios da Microrregião de Itaparica.

\begin{tabular}{|c|c|c|c|c|c|c|c|}
\hline CIDADE & $\begin{array}{l}\text { DADOS } \\
\text { OBS }\end{array}$ & $\begin{array}{l}\text { DADOS } \\
\text { TRMM }\end{array}$ & DIFERENÇA & $\begin{array}{c}\text { ERRO } \\
\text { MÉDIO }\end{array}$ & REQM & PE & $\begin{array}{c}\text { PERÍODO DOS } \\
\text { DADOS }\end{array}$ \\
\hline $\begin{array}{l}\text { Delmiro } \\
\text { Gouveia }\end{array}$ & $8.313,1$ & $9.270,3$ & 957,2 & 4,69 & 67,02 & 0,987 & $1998 / 2014$ \\
\hline Orocó & $8.196,2$ & $9.521,2$ & 1.325 & 6,49 & 92,77 & 0,974 & $1998 / 2014$ \\
\hline $\begin{array}{c}\text { Belém S. } \\
\text { Francisco (Ibó) }\end{array}$ & $7.936,2$ & $9.504,9$ & $1.568,7$ & 7,69 & 109,83 & 0,961 & $1998 / 2014$ \\
\hline Floresta & $7.914,7$ & $9.511,9$ & $1.597,2$ & 7,83 & 111,83 & 0,959 & $1998 / 2014$ \\
\hline $\begin{array}{c}\text { Santa Maria da } \\
\text { Boa Vista }\end{array}$ & $7.057,2$ & $8.732,5$ & $1.675,3$ & 8,73 & 120,91 & 0,943 & $1999 / 2014$ \\
\hline Floresta (Airi) & $8.267,4$ & $10.230,7$ & $1.963,3$ & 9,62 & 137,46 & 0,943 & $1998 / 2014$ \\
\hline Serra Talhada & $10.459,2$ & $12.443,8$ & $1.984,6$ & 9,73 & 138,95 & 0,964 & $1998 / 2014$ \\
\hline
\end{tabular}




\begin{tabular}{cccccccc}
\hline Parnamirim & $8.898,4$ & $11.035,6$ & $2.137,2$ & 10,48 & 149,63 & 0,942 & $1998 / 2014$ \\
\hline Ibimirim & $9.081,3$ & $11.295,7$ & $2.214,4$ & 10,86 & 155,04 & 0,94 & $1998 / 2014$ \\
\hline $\begin{array}{c}\text { Belém S. } \\
\text { Francisco }\end{array}$ & $6.969,5$ & 9.305 & $2.335,5$ & 11,45 & 163,52 & 0,887 & $1998 / 2014$ \\
\hline Sertânia & $5.814,7$ & 7.247 & $1.432,3$ & 11,94 & 130,75 & 0,938 & $2005 / 2014$ \\
\hline Macururé & $3.593,7$ & $5.126,4$ & $1.532,8$ & 12,77 & 139,92 & 0,815 & $2005 / 2014$ \\
\hline Glória & $3.289,09$ & $4.911,8$ & $1.622,7$ & 13,52 & 148,13 & 0,752 & $2005 / 2014$ \\
\hline Mirandiba & $8.143,9$ & $11.068,7$ & $2.924,8$ & 14,34 & 204,77 & 0,87 & $1998 / 2014$ \\
\hline Inajá & $7.452,9$ & $10.403,8$ & $2.950,9$ & 14,47 & 206,6 & 0,842 & $1998 / 2014$ \\
\hline Curaçá & $3.434,2$ & $5.309,1$ & $1.874,9$ & 15,62 & 171,16 & 0,697 & $2005 / 2014$ \\
\hline Chorrochó & $3.677,1$ & $6.505,6$ & $2.828,5$ & 19,64 & 235,71 & 0,4 & $2003 / 2014$ \\
\hline Abaré & $3.534,2$ & $6.735,3$ & $3.201,1$ & 22,23 & 266,76 & 0,168 & $2003 / 2014$ \\
\hline
\end{tabular}

Podemos perceber que a pontuação de eficiência não acompanha o erro médio ao longo dos municípios, visto que Sertânia apresenta erro médio mensal maior que Belém de São Francisco, mas pontuação de eficiência melhor. Tal fato, infere-se que apesar da alta diferença entre as estimativas e os dados observados, a alta variabilidade da chuva justifica uma pontuação de eficiência maior, quando comparada a municípios que possuem altas diferenças das estimativas, mas com baixa variabilidade da chuva.

Observando a Tabela 2, podemos verificar que não há uma diferença entre as entidades operadoras, visto que todos os postos pluviométricos foram operados pela CPRM, exceto o posto localizado em Macururé que foi pelo IPA. Sugere-se que, a princípio, o modo de coleta não influenciou na qualidade dos dados, visto que o posto pluviométrico que teve as melhores correlações com as estimativas mantém como modo de coleta o tipo convencional, no município de Delmiro Gouveia e o segundo melhor resultado foi no município de Orocó, cujo método foi integrado ao longo de sua série histórica com o método convencional e telemétrica. Segundo os relatórios das manutenções das estações, disponibilizados pela ANA, alguns postos possuem ao longo de sua série histórica os dois métodos de coleta, utilizando em sua maioria a partir de 2010, a telemetria.

Tabela 2 - Erro médio entre as estimativas e os dados observados em ordem crescente $(\mathrm{mm} / \mathrm{mês})$, entidade operadora dos postos pluviométricos e o modo de coleta dos pluviômetros.

\begin{tabular}{cccc}
\hline CIDADE & $\begin{array}{c}\text { ERRO } \\
\text { MÉDIO }\end{array}$ & $\begin{array}{c}\text { ENTIDADE } \\
\text { OPERADORA }\end{array}$ & MODO DE COLETA \\
\hline Delmiro Gouveia & 4,69 & CPRM & CONVENCIONAL \\
Orocó & 6,49 & CPRM & CONVENCIONAL/TELEMÉTRIC \\
Belem S. Francisco & 7,69 & CPRM & CONVENCIONAL/TELEMÉTRIC \\
(Ibó) & 7,63 & CPRM & CONVENCIONAL/TELEMÉTRIC \\
Floresta & 7,83 & $\mathrm{~A}$ \\
\hline
\end{tabular}




\begin{tabular}{cccc}
\hline $\begin{array}{c}\text { Santa Maria da Boa } \\
\text { Vista }\end{array}$ & 8,73 & CPRM & $\begin{array}{c}\text { CONVENCIONAL/TELEMÉTRIC } \\
\text { A }\end{array}$ \\
$\begin{array}{c}\text { Floresta (Airi) } \\
\text { Serra Talhada }\end{array}$ & 9,62 & CPRM & CONVENCIONAL/TELEMÉTRIC \\
Parnamirim & 9,73 & CPRM & CONVENCIONAL \\
Ibimirim & 10,48 & CPRM & CONVENCIONAL \\
Belem S. Francisco & 10,86 & CPRM & CONVENCIONAL \\
Sertania & 11,45 & CPRM & CONVENCIONAL/TELEMÉTRIC \\
Macururé & 11,94 & CPRM & CONVENCIONAL/TELEMÉTRIC \\
Glória & 12,77 & IPA & A \\
Mirandiba & 13,52 & CPRM & CONVENCIONAL \\
Inajá & 14,34 & CPRM & CONVENCIONAL/TELEMÉTRIC \\
Curaçá & 14,47 & CPRM & CONVENCIONAL/TELEMÉTRIC \\
Chorrochó & 15,62 & A \\
Abaré & 19,64 & CPRM & CONVENCIONAL/TELEMÉTRIC \\
& 22,23 & CPRM & CONVENCIONAL/TELEMÉTRIC \\
\hline & & CPRM & C \\
\hline & & & CONVENCIONAL \\
\hline
\end{tabular}

Diante das análises obtidas, percebe-se que a tecnologia integrada ao posto pluviométrico não está associada a melhores estimativas, inferindo que outros fatores podem estar associados a erros consideráveis.

\subsection{RELAÇÃO DAS CHUVAS CONVECTIVAS E ESTRATIFORMES COM AS DIFERENÇAS ENTRE AS ESTIMATIVAS E A PRECIPITAÇÃO OBSERVADA EM BELÉM DO SÃO FRANCISCO}

No que concerne a média mensal da taxa de precipitação convectiva, o seu maior pico ao longo do ano é no mês de março $(4,12 \mathrm{~mm} / \mathrm{hr})$, coincidindo com o mês mais chuvoso de Belém de São Francisco ( $91,9 \mathrm{~mm}$ ). Em compensação a menor taxa convectiva foi em setembro, mês mais seco do município (Figura 4). A maior taxa de chuva estratiforme é no mês de março $(1,23 \mathrm{~mm} / \mathrm{hr})$, assemelhando-se com a taxa convectiva. No entanto, a maior taxa dessa chuva aproxima-se do valor encontrado no mês de dezembro que é de $1,15 \mathrm{~mm} / \mathrm{hr}$. 


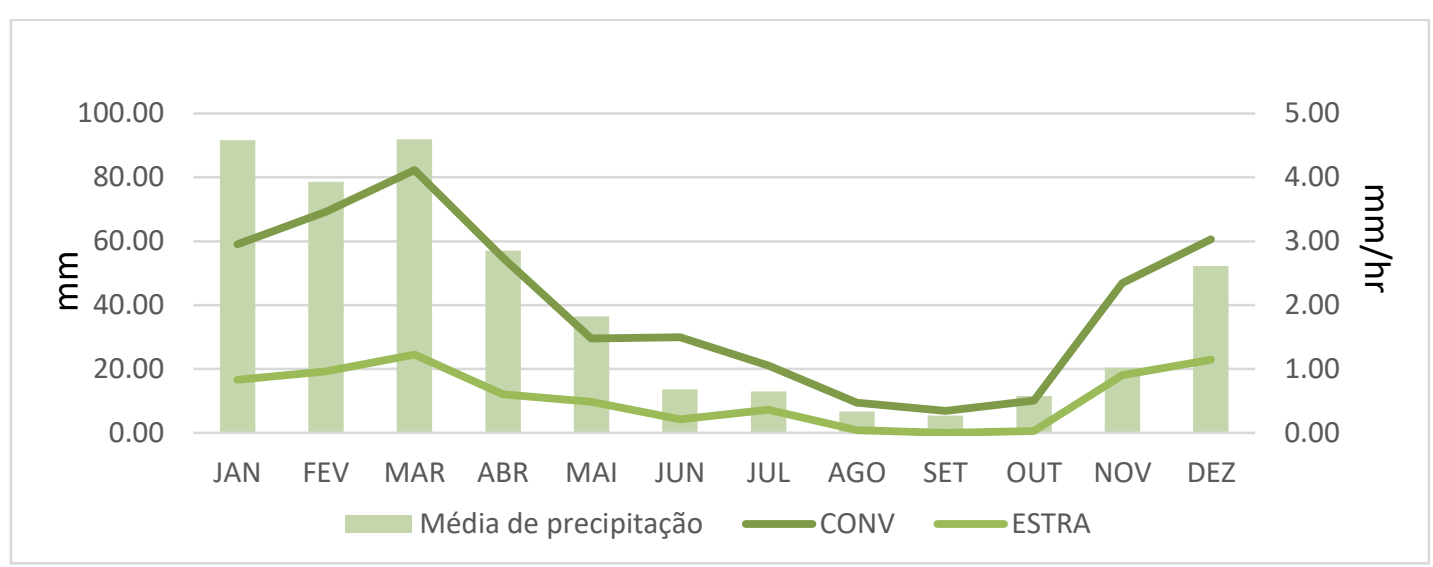

Figura 04 - Média, entre 1998 e 2014, da precipitação observada e estimada e taxa de chuva convectiva e estratiforme.

Anjos et al. (2016) encontraram valores semelhantes em Petrolândia, um dos municípios que compõe a Microrregião de Itaparica, onde as taxas de chuvas convectivas têm seu maior pico no mês de março, coincidindo o mesmo com as taxas de chuvas estratiformes.

Um aspecto a ser considerado acerca da acurácia das estimativas, é sua relação com a proporção dos tipos de chuvas. Baseando-se na linha de tendência, percebe-se que quanto maior for a proporção das taxas médias mensais estratiformes, menor será a proporção da diferença diante da média total de precipitação entre a estimativa e os dados observados (Figura 05). Ou seja, os menores erros - proporcionais a média total mensal de precipitação tenderão a ser encontrados em meses onde a chuva estratiforme predomina. $O$ objetivo de analisar as diferenças por meio da sua parcela (valores percentuais) em relação à média mensal de precipitação, evita que valores absolutos altos sejam interpretados sem levar em consideração se o mês é chuvoso ou seco.

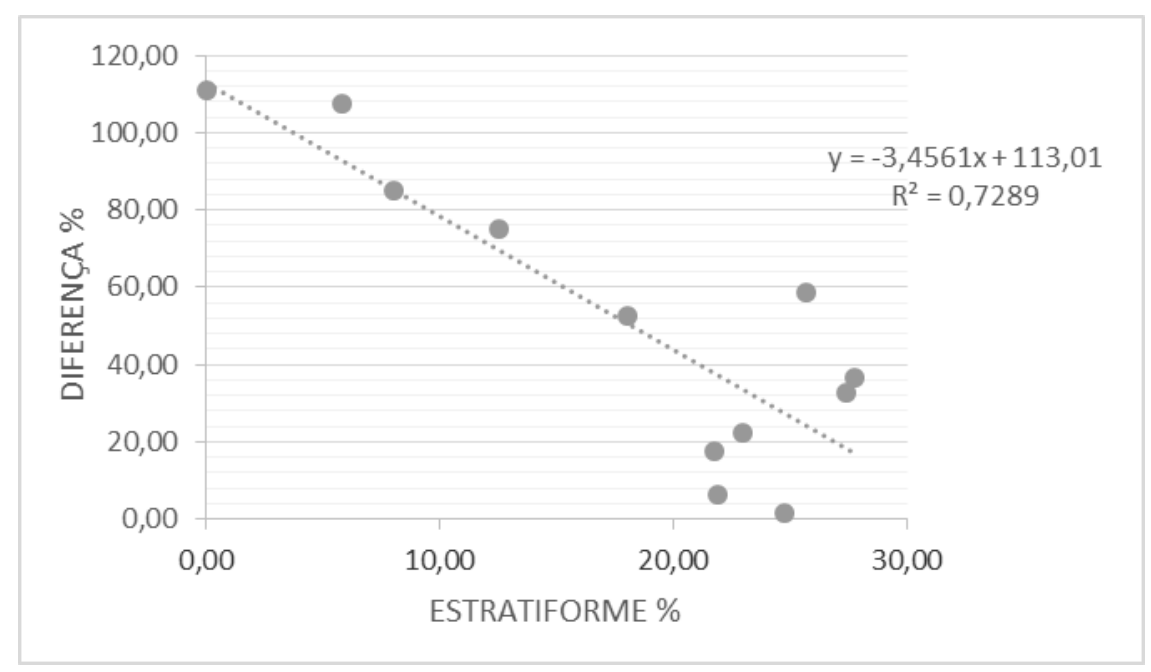

Figura 05 - Linha de tendência e correlação entre a proporção das taxas mensais de estratiformes (\%) com a proporção da diferença em relação a média total entre as estimativas e os dados observados. 
Por ser uma área com predominância de precipitação convectiva, se comparada com outras regiões do estado de Pernambuco, as estimativas tendem a serem superestimadas. Isso pode ser evidenciado quando as chuvas estratiformes estão em maiores proporções, as superestimações tendem a ser menores, fazendo com que as diferenças entre os dados diminuam.

Poder-se-ia sugerir que devido as taxas de chuvas convectivas serem mais atuantes durante a estação chuvosa, a relação verdadeira seria da quantidade precipitada. No entanto, a relação entre a quantidade precipitada e a proporção da diferença em relação a média mensal é menor que as das taxas convectivas com as diferenças mensais (Figura 06), apresentando o fato de que apenas $57 \%$ da variável dependente consegue ser explicada pelos regressores presentes no modelo.

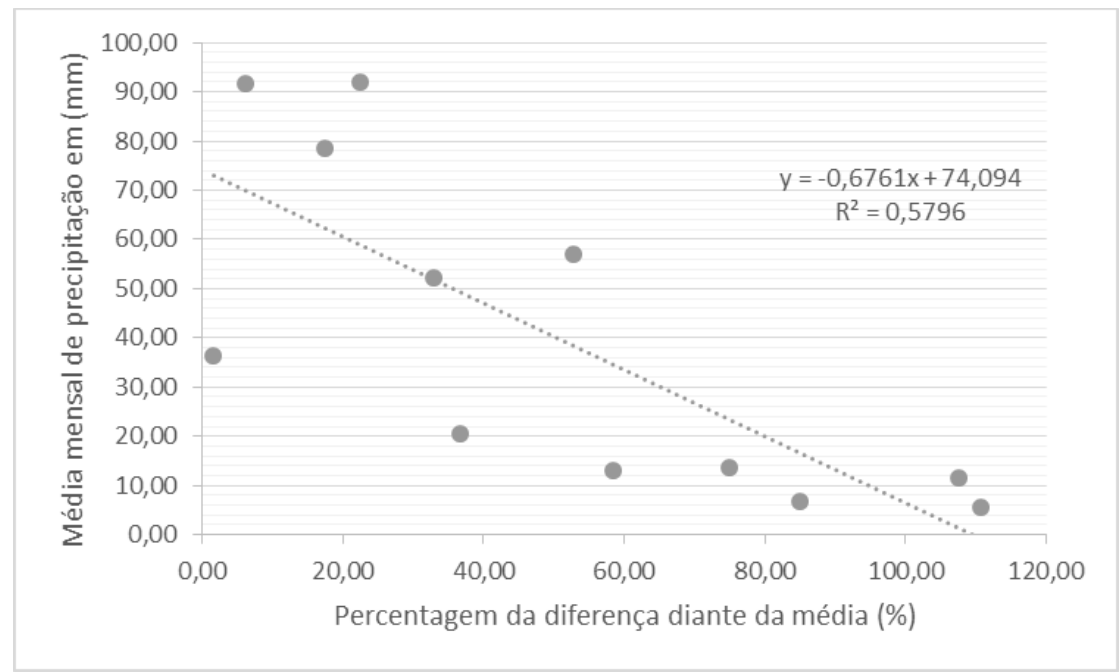

Figura 06 - Linha de tendência e correlação entre a média mensal de precipitação e a proporção da diferença diante da média mensal de precipitação.

É importante ressaltar que tais análises permitem sugerir que as taxas de precipitação convectiva e estratiforme interferem na acurácia das estimativas para médias mensais, podendo ter outra configuração se incluírem médias anuais ou até mesmo diárias. Na Figura 07, a proporção de taxas anuais de chuvas convectivas não interfere na proporção da diferença diante da média anual de precipitação de 1998 a 2014. Um dos motivos para não correlação entre as variáveis, diferentemente com as médias mensais, estaria na existência de valores de taxas dos tipos de chuvas discrepantes dentro de um ano, o que não acontece quando se elabora as médias mensais, quando as taxas tendem a ser semelhantes entre si, em meses iguais. Portanto, se em um ano apresentar em um determinado mês uma taxa de chuva convectiva alta e nos meses seguintes terem taxas mais baixas, irão refletir em uma média anual da taxa convectiva que "oculta" os valores mais altos. 


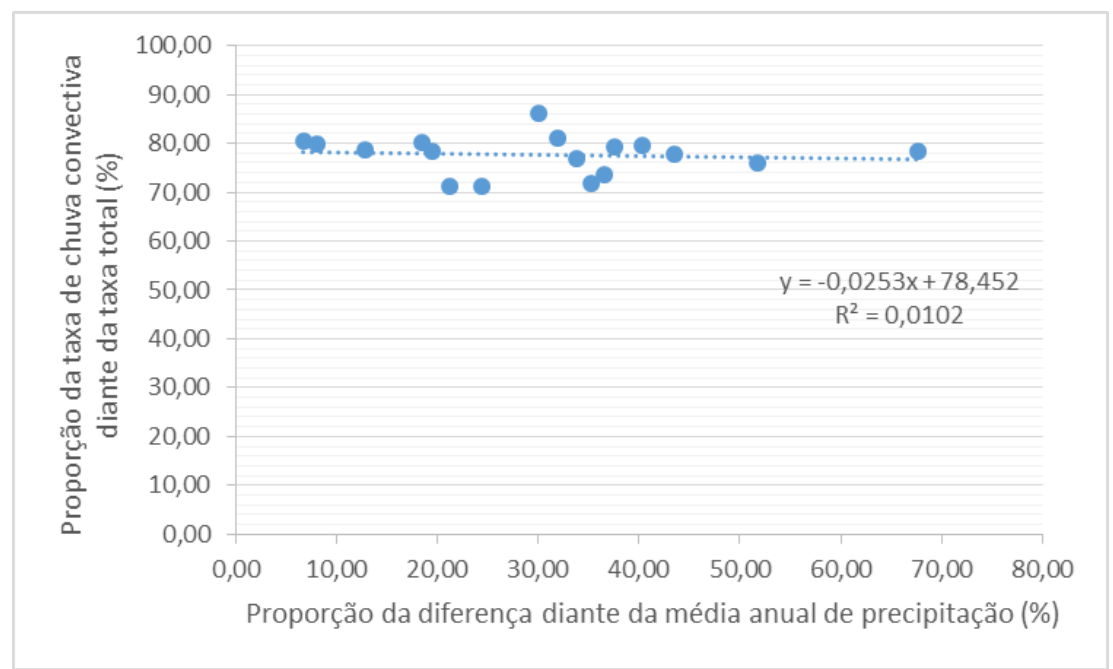

Figura 07 - Proporção das médias anuais de 1998 a 2014 das taxas convectivas e a sua relação com a proporção da diferença diante da média anual de precipitação estimada e observada.

\section{CONSIDERAÇÕES FINAIS}

Considerando o entorno e a Microrregião de Itaparica, o município de Delmiro Gouveia foi o que teve as melhores correlações entre os municípios pesquisados. Em relação aos municípios da microrregião de Itaparica, o posto localizado na sede do município de Belém de São Francisco foi o que teve as menores correlações estatísticas, e as maiores, no distrito de Ibó. Isso mostra que não houve um determinado padrão espacial da acurácia das estimativas.

Em relação ao período utilizado dos dados, não foi identificada nenhuma relação com a acurácia dos dados, visto que pontos com séries históricas diferentes apresentaram valores semelhantes em alguns casos.

Foi observado que as qualidades dos instrumentos nos postos pluviométricos não interferem em maiores aproximações com as estimativas do satélite TRMM. Essa afirmação vem do fato que o município com a maior correlação estatística com as estimativas, Delmiro Gouveia, possui como método de coleta de dados o convencional. Além disso, municípios que tiveram baixas correlações, como Curaçá e Chorrochó, possuem como método de coleta, a associação entre o convencional e o telemétrico, ao longo da série de dados.

Existe uma relação considerável entre maiores proporções de chuvas mensais estratiformes e menores proporções das diferenças diante da média total de precipitação. Isso pode ser evidenciado quando as chuvas estratiformes estão em maiores proporções, as superestimações tendem a ser menores, fazendo com que as diferenças entre os dados diminuam. Poder-se-ia acreditar que a quantidade de chuva seria a responsável por maiores diferenças, no entanto, não há uma correlação considerável que apresente isso. É válido considerar que não existe relação entre as taxas anuais de chuvas convectiva com as diferenças entre as estimativas e os dados observados, inferindo que as discrepâncias dentro de um ano podem interferir no resultado dessa correlação. 


\section{AGRADECIMENTOS}

Agradecemos a Coordenação de Aperfeiçoamento de Pessoal de Nível Superior (CAPES) pelo financiamento da pesquisa.

\section{REFERÊNCIAS}

AB' SABER, A. N. Os domínios de natureza no Brasil: potencialidades paisagísticas. São Paulo: Ateliê Editorial, 2003. 146 p.

ANJOS, R. S.; NÓBREGA, R. S.;ARAÚJO, F. E.; ROCHA FILHO, G. B. R. Spacial distribution of rain types in Pernambuco with the usage of Remote Sensing. Journal of Hyperspectral Remote Sensing v.6, n.3 (2016) 154-163..

ANJOS, R. S.; NÓBREGA, R. S. Validando os dados de estimativa de precipitação por sensoriamento remoto do satélite TRMM para Pernambuco - Brasil. In: I Workshop em Ciências da Terra e do Espaço, Évora, Portugal, 2013, p. 129-136.

ANJOS, R.S.; CANDEIAS, A. L. B.; NÓBREGA, R. S. Caracterização das chuvas através do satélite TRMM em Petrolândia-PE. Revista Brasileira de Climatologia, v.18, p.307-326, 2016.

ANJOS, R. Qualidade de dados do satélite TRMM para espacialização das chuvas na microrregião de Itaparica.. 2017. 100 f. Dissertação. Centro de Tecnologia e Geociências, Universidade Federal de Pernambuco, Recife. 2017

ARAÚJO, R. S. Classificação climatológica das nuvens precipitantes no Nordeste Brasileiro utilizando dados do radar a bordo de um satélite TRMM. Dissertação de Mestrado. Instituto Nacional de Pesquisas Espaciais.2015.129 p.

AYOADE, J. O. Introdução à climatologia para os trópicos. 14a ed. Rio de Janeiro: Bertrand Brasil, 2010. 350 p.

CEMADEN. Pluviômetros. Disponível em: < http://www.cemaden.gov.br/o-quesao-pluviometros/>. Acesso em outubro de 2016.

COLLISCHONN, B. Uso de precipitação estimada pelo satélite TRMM em modelo hidrológico distribuído. Dissertação de Mestrado. Universidade Federal do Rio Grande do Sul. Porto Alegre (RS). 2006. 128 p.

COSTA, A. N. M.; SOUSA, A. M. L.; Análise do uso e mudança do solo a partir dos dados de vazão e precipitação. Anais do $10^{\circ}$ Seminário Anual de Iniciação Científica da UFRA, 2012.

DINKU, T.; CECCATO, P.; GROVER-KOPEC, E.; LEMMA, L.; CONNOR, S. J.; ROPELLEWSKI, C. F. Validation of satellite rainfall products over East Africa's complex topography. International Journal of Remote Sensing, vol. 28, no. 7, 10 April. 2007.

DUAN, Y.; WILSON, A. M.; BARROS, A. P. Scoping a field experiment: error diagnostics of TRMM precipitation radar estimates in complex terrain as a basis for IPHEx2014. Journal Hydrology and Earth System Sciences., 19. 2015. p. 1501-1520.

FUZZO, D. F. S.; PANTANO, A. P.; CAMARGO, M. B. P. Modelagem Agrometeorológica para Estimativa de Produtividade de Soja para o Vale do 
Médio Paranapanema-SP. Revista Irriga, Botucatu, v. 20, n. 32015. , p. 490501.

IBGE. Cidades. Disponível em: <http://cidades.ibge.gov.br/xtras/perfil.php?cod umn $=261160>$. Acesso em julho de 2016 .

INDU, J.; KUMAR, D. N. Evaluation of TRMM precipitation products over Indian Subcontinent. The International Archives of the Photogrammetry, Remote Sensing and Spatial Information Sciences, Volume XL-8. 2014. p. 355 -358.

JAVANMMARD, S.; JAMLI, B. The Study of Atmospheric Physics Parameters over Iran Using Satellite TRMM-TMI. Journal Earth Science Climatic Change, v. 6, p 17, 2015.

KUMMEROW, C. et al. The status of the Tropical Rainfall Measuring Mission. Mission (TRMM) after two years in orbit. Journal of Applied Meteorology, 39 (12) . 2000. p. 1965-1982.

LOUZADA, F. L. R. O.; XAVIER, A. C.; PEZZOPANE, J. E. M. Análise da precipitação estimada por satélite para a bacia hidrográfica do Rio Doce. Anais XVII Simpósio Brasileiro de Sensoriamento Remoto - SBSR, João Pessoa-PB, Brasil, 2015, p $6645-6652$.

MORALES, C. A.; ALBRECHT, R. I. Tropical Rainfall Measuring Mission (TRMM): Missão para medição da chuva tropical. Disponível em: http://docplayer.com.br/1747860-Tropical-rainfall-measuring-missiontrmm.html Acesso em: agosto de 2014.

NASA. NASA Facts: TRMM Instruments. Disponível em: http://trmm.gsfc.nasa.gov/overview_dir/ceres.html. Acesso em julho de 2015.

NETO, L. A. S.; NÓBREGA, R. S. Conversão dos dados diários do TRMM de formato binário para texto. In: XVI Congresso Brasileiro de Agrometeorologia, 2009. Disponível em < www.sbagro.org.br/ anais_ congresso _2009/cba2009/301.pdf>. Acesso em setembro de 2015. Anais XIV Simpósio Brasileiro de Sensoriamento Remoto, Natal, Brasil, 2009. p. 4781-4788.

NÓBREGA, R. S.; SOUZA, E. P.; GALVÍNCIO, J. D. Análise da estimativa de precipitação do TRMM em uma Sub-Bacia da Amazônia. Revista de Geografia. Recife: UFPE - DCG/NAPA, v. 25, no 1, jan/abr. 2008.

OCHOA, A.; PINEDA, L.; CRESPO, P.; WILLEMS, P. Evaluation of TRMM 3B42 precipitation estimates and WRF retrospective precipitation simulation over the Pacific-Andean region of Ecuador and Peru. Hydrol. Earth Syst. Sci., 18, 2014. p. 3179-3193.

OLIVEIRA, C. Identificação e correção da banda brilhante em dados de radar meteorológico. Dissertação de Mestrado. Universidade Federal do Paraná. Curitiba (PR). 2014. 75 p.

PARK, M. S. et al. Regional cloud characteristics over the tropical northwestern Pacific as revealed by Tropical Rainfall Measuring Mission (TRMM) Precipitation Radar and Microwave Imager. Journal of Geophysical research, vol. 112, 2007.

PEREIRA et al. Avaliação dos Dados de Precipitação Estimados pelo SatéliteTRMM para o Brasil. Revista Brasileira de Recursos Hídricos Volume 18 n.3, p. 139-148, 2013. 
SOARES, A. S. D.; PAZ, A. R.; PICILLI, D. G. A. Avaliação das estimativas de chuva do satélite TRMM no Estado da Paraíba. Revista Brasileira de Recursos Hídricos, v 21, p. 288 - 299, 2016.

UFCG. Clima. Disponível em < http://www.dca.ufcg.edu.br/tsm.htm>. Acesso em dezembro de 2016 